\title{
Effect of cataract surgery on quality of life for patients with severe vision impairment due to age-related macular degeneration
}

\author{
Claudia Taipale ${ }^{1,2}$, Andrzej Grzybowski ${ }^{3,4}$, Raimo Tuuminen ${ }^{1,5}$ \\ ${ }^{1}$ Helsinki Retina Research Group, University of Helsinki, Helsinki, Finland; ${ }^{2}$ Department of Ophthalmology, Helsinki University Hospital, Helsinki, \\ Finland; ${ }^{3}$ Department of Ophthalmology, University of Warmia and Mazury, Olsztyn, Poland; ${ }^{4}$ Institute for Research in Ophthalmology, Foundation \\ for Ophthalmology Development, Poznan, Poland; ${ }^{5}$ Unit of Ophthalmology, Kymenlaakso Central Hospital, Kotka, Finland \\ Contributions: (I) Conception and design: All authors; (II) Administrative support: A Grzybowski, R Tuuminen; (III) Provision of study materials \\ or patients: R Tuuminen; (IV) Collection and assembly of data: C Taipale, R Tuuminen; (V) Data analysis and interpretation: All authors; (VI) \\ Manuscript writing: All authors; (VII) Final approval of manuscript: All authors. \\ Correspondence to: Raimo Tuuminen, MD, PhD, FEBO. Associate Professor, Chief Physician, Unit of Ophthalmology, Kymenlaakso Central Hospital, \\ Kotkantie 41, FI-48210 Kotka, Finland. Email: raimo.tuuminen@helsinki.fi.
}

Background: To determine whether patients with severe vision impairment due to advanced age-related macular degeneration (AMD) benefit from bilateral cataract surgery in terms of vision-related quality of life (QoL).

Methods: A prospective interventional single-center study. Ten patients with severe vision impairment due to advanced bilateral AMD were included. The preoperative corrected distance visual acuity (CDVA) was $\geq 1.0 / \geq 1.0$ LogMAR units on Snellen chart and $<20 /<20$ points on Early Treatment Diabetic Retinopathy Study (ETDRS) chart. Patients were not on active treatment for wet AMD as the treatment was expected to have no effect or benefit. The patients were scheduled for immediate sequential bilateral cataract surgery, with target refraction emmetropia (SN60WF, Alcon). Vision-related QoL was measured with National Eye Institute Visual Functioning Questionnaire-25 (NEI VFQ-25) preoperatively, at 3 months and 1 year.

Results: The mean age of the patients was $82.5 \pm 6.2$ years. The mean NEI VFQ-25 overall composite score changed from $44.0 \pm 7.1$ preoperatively to $54.9 \pm 13.7$ at 3 months and to $56.9 \pm 15.6$ at 1 year $(P=0.045$, Friedman test). During the 1-year follow-up, there was an improvement in the subscale scores indicating difficulty with peripheral vision, mental health symptoms, and role difficulties due to vision $(\mathrm{P}<0.05$ for all, Wilcoxon sign-rank test).

Conclusions: Cataract surgery may improve the vision-related QoL in patients with severe vision impairment due to bilateral advanced AMD.

Keywords: Age-related macular degeneration (AMD); cataract surgery; geographic atrophy (GA); vision impairment; vision-related quality of life (vision-related QoL)

Submitted Jan 21, 2020. Accepted for publication Apr 30, 2020.

doi: $10.21037 /$ atm-2020-965

View this article at: http://dx.doi.org/10.21037/atm-2020-965

\section{Introduction}

Cataract surgery has been shown to significantly improve vision-specific functioning and vision-related quality of life (QoL) for most patients (1). However, patients undergoing cataract surgery often have coexistent eye diseases that lead to worse outcomes because of lower potential for visual function (2).

Age-related macular degeneration (AMD) is a common ocular comorbidity in patients undergoing cataract surgery and it has been shown to relate to inferior outcomes concerning visual acuity (VA) and patient satisfaction compared to patients with no coexistent eye diseases (3-5). 
Nonetheless, a number of studies have shown that patients with AMD benefit from cataract surgery in terms of VA and vision-related QoL (6-12). Yet, it is poorly defined which subset of patients with AMD is likely to benefit from cataract surgery. Studies showing favorable outcomes on visual function and QoL from cataract surgery have concentrated mostly on patients with mild to moderate AMD (7-10). It is more controversial, whether patients with advanced AMD and very poor preoperative VA benefit from the procedure $(6,13)$.

In this study, we aimed to determine whether cataract surgery has an effect on the vision-related QoL for patients with severe vision impairment due to advanced bilateral AMD.

\section{Methods}

\section{Study design}

The study was a prospective interventional singlecenter study. It was conducted in the Department of Ophthalmology, Kymenlaakso Central Hospital, Kotka, Finland.

The diagnostics and treatment of AMD followed the national Current Care Guidelines (14). Ten consecutive patients with severe vision impairment due to bilateral advanced AMD were included in the study. The World Health Organization classification of severity of vision impairment based on VA was used (15). The patients were scheduled for immediate sequential bilateral cataract surgery and the operations were performed between September 2016 and December 2017.

The main outcome measure was vision-related QoL, which was recorded preoperatively, at 3 months and 1 year with National Eye Institute Visual Functioning Questionnaire-25 (NEI VFQ-25) (16). A research technician administered the questionnaire by interview. Items 15 and 16 regarding driving ability were not questioned.

The study was conducted according to the tenets of the Declaration of Helsinki and was approved by the Research Director and Chief Medical Officer of the Kymenlaakso Central Hospital and the Institutional Review Board of Helsinki University Hospital. A written consent was obtained from all the patients included in the study. Confidentiality of the patient records was maintained while entering the data into a computer-based standardized database for analysis.

\section{Inclusion criteria}

Patients aged 60-90 years with severe vision impairment due to bilateral advanced AMD [corrected distance visual acuity (CDVA) of both eyes $\geq 1.0 / \geq 1.0$ LogMAR units on Snellen chart and $<20 /<20$ points on Early Treatment Diabetic Retinopathy Study (ETDRS) chart]. The patients had coexisting bilateral age-related cataracts in both eyes and were eligible for cataract surgery under the Current Care Guidelines of Cataract Surgery of the Finnish Medical Society, Duodecim.

\section{Exclusion criteria}

Criteria for exclusion were active or previous retinal vein or artery occlusion, diabetic retinopathy, retinal detachment or tear, retinal necrosis, vitritis, endophthalmitis, vitreous hemorrhage, optic neuritis, any type of glaucoma, periocular infection, intraocular procedure (excluding intravitreal anti-VEGF injections), myopia above -6.0 diopters, alcohol abuse and thyroid disease with abnormal thyroid-stimulating hormone (TSH) levels. Exclusion criteria also included intraoperative complications such as sutures, posterior capsule tear or iris prolapse.

\section{Patients}

A total of 10 patients (20 eyes) were enrolled in the study. The patients were scheduled for immediate sequential bilateral cataract surgery and the operations were performed between September 2016 and December 2017. One patient was operated between January and March, two patients between April and June, three patients between July and September and four patients between October and December. In patients with wet AMD, anti-VEGF treatment had been discontinued previously for having no effect and no expectations for improvement of the patient's ability to function or QoL. Vision rehabilitation services were available for all patients.

One patient could not answer the postoperative questionnaire due to severely impaired hearing and therefore withdrew from the study. The baseline data was evaluated according to intention-to-treat analysis.

\section{Clinical examination}

Clinical examination included bilateral CDVA testing at standardized light conditions, biomicroscopy, tonometry and 
examination of the fundus. The classification for very low VA was on a semi-quantitative scale such as hand motion (HM) and counting fingers (CF). For statistical purposes, the Snellen values were transformed to the equivalent LogMAR units. The very low VA measurements were converted as follows: HM 2.3 and CF 1.9 LogMAR (17). Central retinal thickness (CRT) and the existence of intraretinal fluid (IRF) and subretinal fluid (SRF), pigment epithelial detachment (PED), subretinal fibrosis and geographic atrophy (GA) was recorded by spectral-domain optical coherence tomography (SD-OCT; Heidelberg Eye Explorer Version 199.10.0 and HRA/SPECTRALIS ${ }^{\circledR}$ Viewing Module Version 6.0.9.0, Heidelberg Engineering GmbH, Heidelberg, Germany).

The type and severity of cataract were graded according to the WHO simplified cataract grading system to three levels reflecting progressive severity (18). The grading was performed preoperatively by a single surgeon.

\section{NEI VFQ-25}

Vision-related QoL was recorded preoperatively, at 3 months and 1 year with NEI VFQ-25 (16).

The NEI VFQ-25 questionnaire generates the following vision targeted sub-scales: general vision, ocular pain, difficulty with near vision activities, difficulty with distance vision activities, limitations in social functioning due to vision, mental health symptoms due to vision, role limitations due to vision, dependency on others due to vision, driving difficulties (not included in this study), limitations with color and peripheral vision. VFQ-25 additionally includes a single question rating general health. The overall composite score for the VFQ-25 is an average from the vision-targeted subscale scores excluding the general health rating question. In all items a higher score corresponds with better functioning.

\section{Surgery and target refraction}

Biometry was evaluated on the day of surgery using sweptsource optical coherence tomography (SSOCT) technology (OA-2000; Tomey GmbH, Nürnberg, Germany), and the Haigis formula with optimized constants was used for IOL calculations.

A standardized phacoemulsification technique was used in all cataract surgeries, as described in Danni et al. (hrrg. fi/en/videos/cataract/) (19). All patients were operated by a single surgeon. Anesthesia was topical in all cases. Preloaded aspheric hydrophobic blue-light filtering singlepiece monofocal intraocular lenses were used (AU00T0, AcrySof ${ }^{\circledR}$ IQ, SN60WF in UltraSert ${ }^{\mathrm{TM}}$ delivery system, Alcon). Intracameral cefuroxime was used as antimicrobial medication (Aprokam ${ }^{\circledR}$, Laboratoires Théa, ClermontFerrand, France). Duration of the operation and phacoemulsification energy [cumulative dissipated energy $(\mathrm{CDE})]$ were recorded.

No topical antimicrobial medication was used postoperatively. Non-steroidal anti-inflammatory drug (NSAID) monotherapy was used as the postoperative antiinflammatory medication. Target refraction was emmetropia for all patients. Spectacle update (up-to-date near and distance correction) 1 month postoperatively was advised.

\section{Statistical analyses}

Data are given as mean \pm standard deviation for parametric variables, median with range for non-parametric variables, and absolute numbers with proportions for nominal variables. IBM Statistics 24 (IBM Corp., Armonk, NY, USA) was used for statistical analysis. Non-parametric QoL variables were analyzed using the Friedman test to detect differences across multiple time points, and the Wilcoxon sign-rank test was used for comparisons at a given timepoint. $\mathrm{P} \leq 0.05$ was considered statistically significant.

\section{Results}

\section{Baseline variables}

Baseline variables regarding patient age and gender, cessation of active treatment, refraction, CDVA, CRT, operation time, phacoemulsification energy are presented in Table 1. Preoperative cataract classification and macular status are presented in Table 2. Preoperative optical coherence tomography images are shown in Figure 1.

\section{Effect of bilateral cataract surgery on vision-related QoL}

In patients with bilateral advanced AMD, the mean NEI VFQ-25 overall composite score was $44.0 \pm 7.1$ at baseline, $54.9 \pm 13.7$ at 3 months, and $56.9 \pm 15.6$ at 1 year $(\mathrm{P}=0.045$, Friedman test, Table 3). During the 3-month follow-up, the subscale scores indicating difficulty with near activities $(\mathrm{P}=0.046$, Wilcoxon sign-rank test, Table 3), role difficulties $(\mathrm{P}=0.038$, Table 3$)$ and dependency due to vision $(\mathrm{P}=0.026$, 
Table 1 Baseline variables

\begin{tabular}{lc}
\hline & $\begin{array}{c}\text { Late-stage AMD } \\
(\mathrm{N}=10 \text { patients/20 eyes) }\end{array}$ \\
\hline Age (years) & $82.5 \pm 6.2[72-89]$ \\
Gender (male: female) & $7: 3$ \\
$\begin{array}{l}\text { Cessation of active } \\
\text { treatment (months) }\end{array}$ & $27.0 \pm 37.8[0-88]$ \\
Refraction (SE) & $0.78 \pm 2.84(-2.13-8.50)$ \\
CDVA (LogMAR) & $1.7 \pm 0.4(1.0-2.3)$ \\
CRT ( $\mu$ m) & $389.4 \pm 125.9[235-630]$ \\
Operation time (min) & $19.5 \pm 10.2[11-47]$ \\
Phaco energy (CDE) & $15.3 \pm 6.3(6.6-33.3)$ \\
\hline
\end{tabular}

Data are given as mean \pm SD and range, or absolute numbers. All patients had bilateral late-stage AMD with CDVA $\geq 1.0 / \geq 1.0$ LogMAR units and $<20 /<20$ points on ETDRS chart before surgery. Cessation of active treatment is the time when active treatment for AMD was no longer administered to either eye. AMD, age-related macular degeneration; SE, spherical equivalent; CDVA, corrected distance visual acuity; CRT, central retinal thickness; CDE, cumulative dissipated energy; ETDRS, Early Treatment Diabetic Retinopathy Study.

Table 3) were improved. During the 1-year follow-up, there was an improvement in the subscale scores indicating difficulty with peripheral vision $(\mathrm{P}=0.035$, Wilcoxon signrank test, Table 3), mental health symptoms $(\mathrm{P}=0.018$, Table 3) and role difficulties due to vision ( $\mathrm{P}=0.028$, Table 3). The NEI VFQ-25 scores of all individual questions are presented in Table $\mathrm{S} 1$.

\section{Discussion}

In clinical practice, the visual prognosis is often poor in patients with advanced AMD and low preoperative VA. The aim of our study was to find out, whether patients with severe vision impairment due to advanced bilateral AMD benefit from immediate sequential bilateral cataract surgery in terms of vision-related QoL. It is essential to provide patients with realistic expectations and information on the effect of cataract surgery on vision-related QoL parameters. These results elucidate the expected outcome of bilateral cataract surgery on different vision-related QoL subscales in patients with severe vision impairment due to advanced bilateral AMD, and can be utilized in deciding whether to offer an operation to patients with uncertain visual prognosis.
Table 2 Preoperative cataract classification and macular status

\begin{tabular}{lc}
\hline & Late-stage AMD (N=20 eyes) \\
\hline Cataract & \\
NS & $1.8 \pm 0.6(1+-3+)$ \\
CC & $0.3 \pm 0.6(-1-2+)$ \\
PSC & $0.3 \pm 0.6(-1-2+)$ \\
Macula, $n$ [\%] & \\
Subretinal fibrosis & $10[50]$ \\
GA & $9[45]$ \\
IRF & $8[40]$ \\
PED & $5[25]$ \\
SRF & $3[15]$ \\
\hline
\end{tabular}

Data are given as mean \pm SD and range, or absolute numbers and proportions. Cataract was graded according to the WHO simplified cataract grading system to three levels reflecting progressive severity. AMD, age-related macular degeneration; NS, nuclear sclerosis; CC, cortical cataract; PSC, posterior subcapsular cataract; GA, geographic atrophy; IRF, intraretinal fluid; PED, pigment epithelial detachment; SRF, subretinal fluid.

Previous studies have shown that patients with mild to moderate AMD benefit form cataract surgery in terms of VA and QoL, but the benefit for patients with advanced AMD is more controversial (7-9). There are only a few studies concentrating on patients with advanced AMD $(6,13)$. Mallah et al. observed an improvement in VA and QoL measured by the Daily Living Tasks Dependent on Vision questionnaire in patients with advanced AMD after cataract surgery. During a follow-up period ranging from 1 to 10 months, the items that were significantly improved included watching television, distinguishing a person's features at arm's length, adjusting to light after being in the dark, and reading street signs and names (13). Ma et al. also showed an improvement in VA and QoL measured by the Chinese-version Low Vision Quality of Life questionnaire after cataract surgery in patients with advanced AMD and at least moderate visual impairment (6). They found that the subscale scores indicating general vision and lighting; mobility; psychological adjustment; and reading, fine work and activities of daily living were improved during the 3-month follow-up (6). In addition to traditional intraocular lenses, different intraocular implants have been developed and have shown promising results in patients with AMD (20). A recent study by Dag et al. reported an increase in VA and QoL measured by NEI VFQ-25 after cataract surgery 

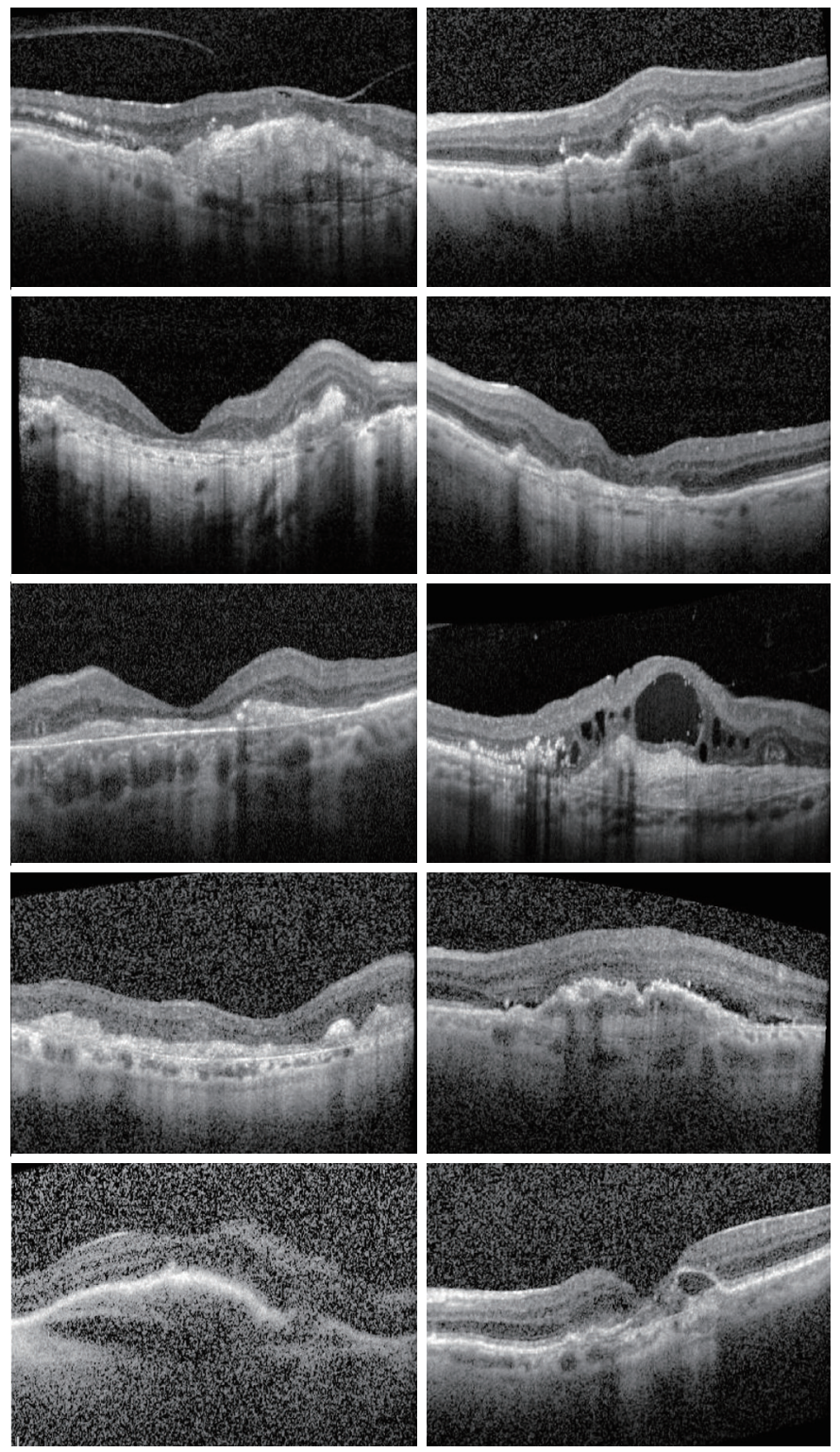

Figure 1 Preoperative optical coherence tomography images.

using a telescopic intraocular lens in patients with advanced AMD. They observed that the parameter for difficulty with activities showed improvement (21).

In our study, the NEI VFQ-25 subscale scores indicating difficulty with peripheral vision, mental health symptoms and role difficulties due to vision were improved during the 1-year follow-up in patients with advanced bilateral AMD, in addition to the improvement in the overall composite score reflecting all vision-targeted subscales. The individual questions that were improved in this group of patients included questions about difficulty noticing objects off
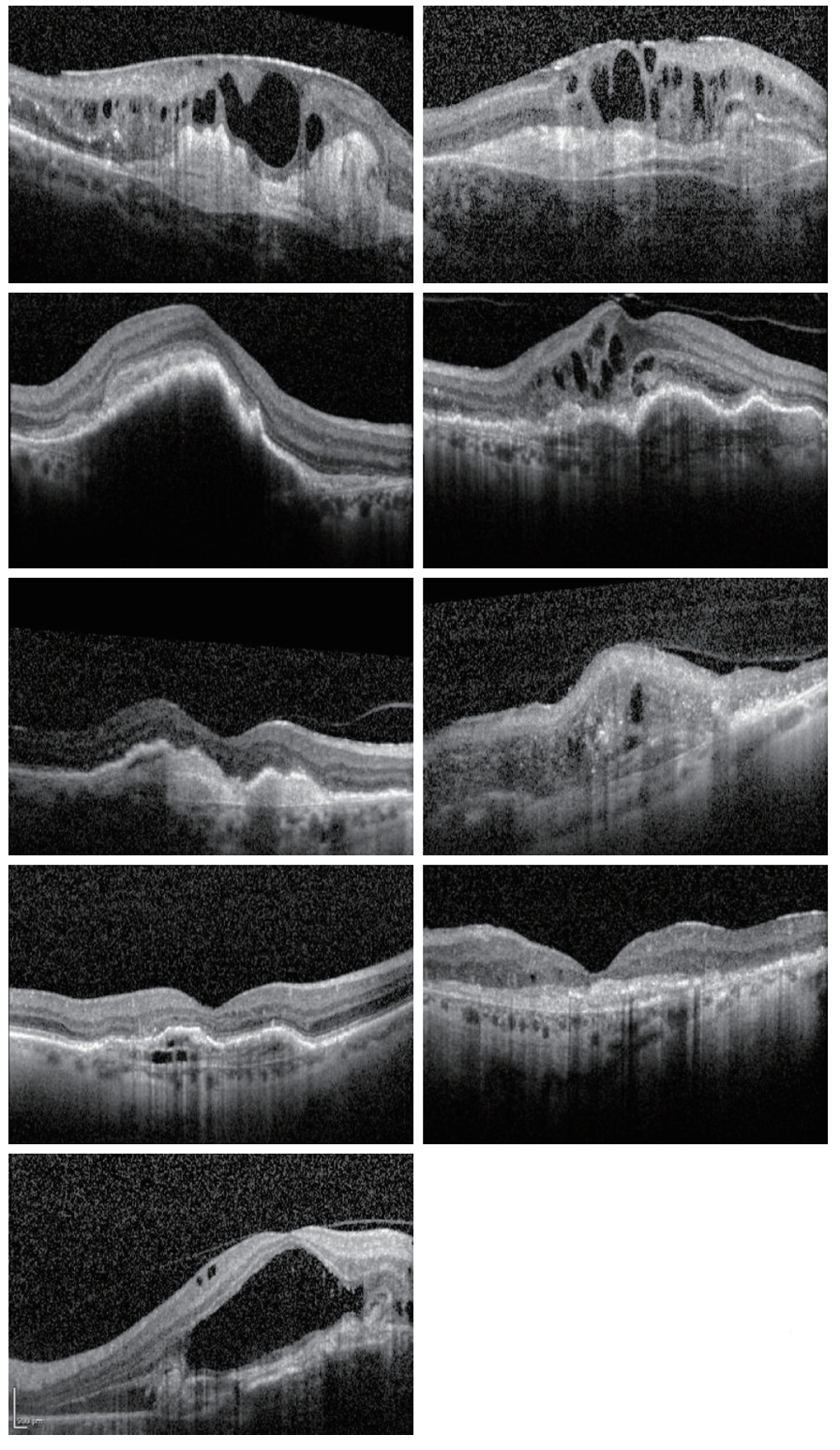
Table 3 The 25-item NEI-VFQ subscale scores

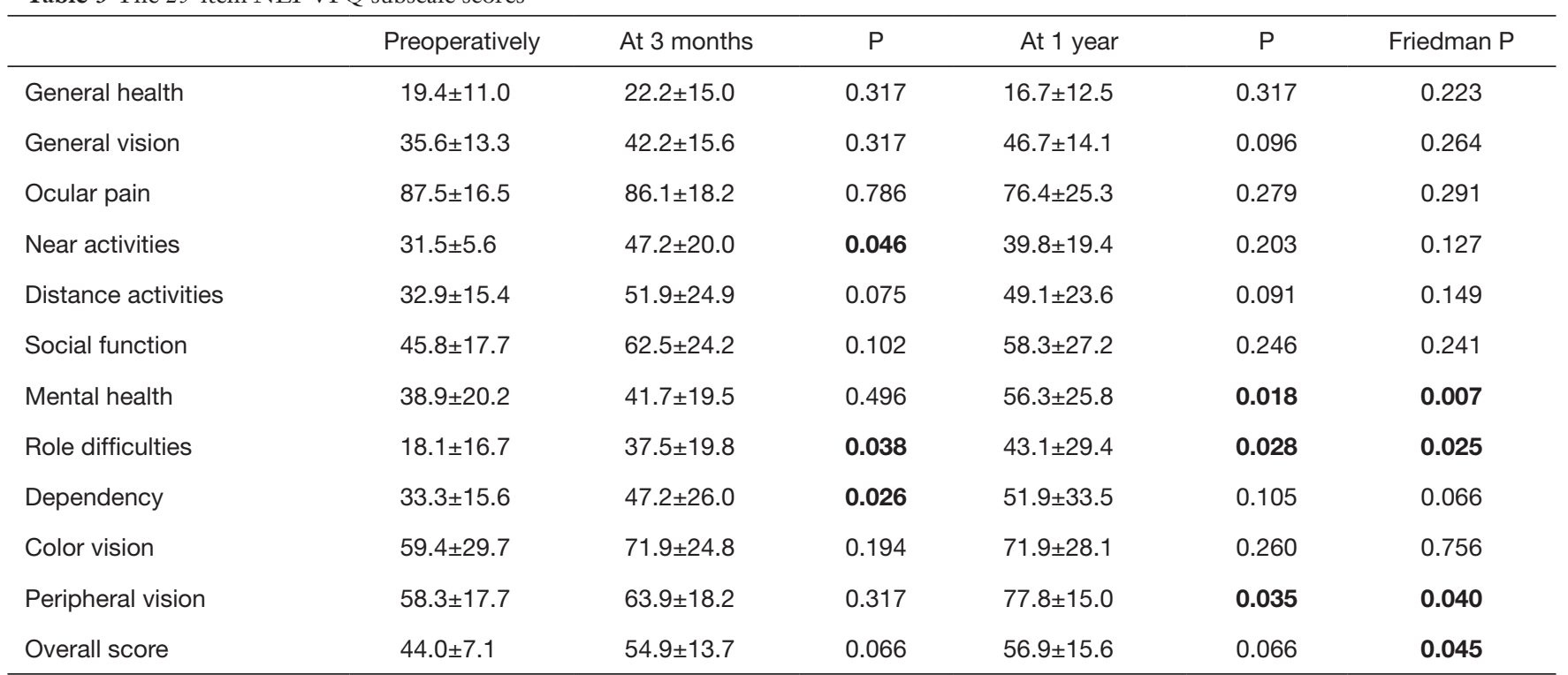

Data are given as mean \pm SD. Bolded text indicates $P \leq 0.05$ was considered statistically significant. Application of the questionnaire was performed together with research technician on the day of immediate sequential bilateral cataract surgery, at 3 months and 1 year. Driving ability (items 15 and 16) were not questioned. The overall score is an average from the vision-targeted subscales excluding the general health rating question. The data was analyzed using Friedman test, and Wilcoxon sign-rank test was used for comparisons at a given timepoint. All patients had bilateral late-stage AMD with CDVA $\geq 1.0 / \geq 1.0$ LogMAR units on Snellen chart and $<20 /<20$ points on ETDRS chart before surgery. NEI-VFQ, National Eye Institute Visual Functioning Questionnaire; AMD, age-related macular degeneration; CDVA, corrected distance visual acuity; ETDRS, Early Treatment Diabetic Retinopathy Study.

study should be seen as a pilot study that could encourage further studies to confirm our findings. Second, the type and severity of cataract varied between the eyes in this study. Consequently, no conclusions can be made on what stage of lens opacities vision-related QoL improvement may be reached. Third, no control group was included in this study. However, the patients were followed for 1 year to minimize the bias of seasonal variation of the subjective judgement on visual function. In conclusion, this study presents results suggesting that bilateral cataract surgery may improve visionrelated QoL and is therefore justified for patients with severe vision impairment due to advanced AMD.

\section{Acknowledgments}

Funding: The study was supported by grants from the Mary and Georg C. Ehrnrooth foundation, Sokeain Ystävätry, the Finnish Eye Foundation, Finnish Medical Foundation, Finnish Ophthalmological Society, Ervald and Hilda Nissi Foundation, the Paulo Foundation, the Waldemar von Frenckell Foundation and the HUS Specific Catchment Area (ERVA) Clinical Research Grants.

\section{Footnote}

Data Sharing Statement: Available at http://dx.doi. org/10.21037/atm-2020-965

Provenance and Peer Review: This article was commissioned by the Guest Editor (Dr. Andrzej Grzybowski) for the series "Recent developments in cataract surgery" published in Annals of Translational Medicine. The article was sent for external peer review organized by the Guest Editor and the editorial office.

Conflicts of Interest: All authors have completed the ICMJE uniform disclosure form (available at http:// dx.doi.org/10.21037/atm-2020-965). The series "Recent developments in cataract surgery" was commissioned by the editorial office without any funding or sponsorship. AG served as the unpaid Guest Editor of the series. The authors have no other conflicts of interest to declare.

Ethical Statement: The authors are accountable for all aspects of the work in ensuring that questions related to the accuracy or integrity of any part of the work are 
appropriately investigated and resolved. The study was conducted according to the tenets of the Declaration of Helsinki and was approved by the Research Director and Chief Medical Officer of the Kymenlaakso Central Hospital and the Institutional Review Board of Helsinki University Hospital. A written consent was obtained from all the patients included in the study.

Open Access Statement: This is an Open Access article distributed in accordance with the Creative Commons Attribution-NonCommercial-NoDerivs 4.0 International License (CC BY-NC-ND 4.0), which permits the noncommercial replication and distribution of the article with the strict proviso that no changes or edits are made and the original work is properly cited (including links to both the formal publication through the relevant DOI and the license). See: https://creativecommons.org/licenses/by-nc-nd/4.0/.

\section{References}

1. Lamoureux EL, Fenwick E, Pesudovs K, et al. The impact of cataract surgery on quality of life. Curr Opin Ophthalmol 2011;22:19-27.

2. Lundström M, Barry P, Henry Y, et al. Visual outcome of cataract surgery; study from the European Registry of Quality Outcomes for Cataract and Refractive Surgery. J Cataract Refract Surg 2013;39:673-9.

3. Kanthan GL, Mitchell P, Burlutsky G, et al. Intermediate- and longer-term visual outcomes after cataract surgery: the Blue Mountains Eye Study. Clin Exp Ophthalmol 2011;39:201-6.

4. Mönestam E, Lundqvist B. Long-term visual outcome after cataract surgery: comparison of healthy eyes and eyes with age-related macular degeneration. J Cataract Refract Surg 2012;38:409-14.

5. Mönestam E, Wachtmeister L. Dissatisfaction with cataract surgery in relation to visual results in a population-based study in Sweden. J Cataract Refract Surg 1999;25:1127-34.

6. Ma Y, Huang J, Zhu B, et al. Cataract surgery in patients with bilateral advanced age-related macular degeneration: measurement of visual acuity and quality of life. J Cataract Refract Surg 2015;41:1248-55.

7. Stock MV, Vollman DE, Baze EF, et al. Functional visual improvement after cataract surgery in eyes with age-related macular degeneration: results of the Ophthalmic Surgical Outcomes Data Project. Invest Ophthalmol Vis Sci 2015;56:2536-40.

8. Armbrecht AM, Findlay C, Aspinall PA, et al. Cataract surgery in patients with age-related macular degeneration: one-year outcomes. J Cataract Refract Surg 2003;29:686-93.

9. Armbrecht AM, Findlay C, Kaushal S, et al. Is cataract surgery justified in patients with age related macular degeneration? A visual function and quality of life assessment. Br J Ophthalmol 2000;84:1343-8.

10. Lundström M, Brege KG, Florén I, et al. Cataract surgery and quality of life in patients with age related macular degeneration. Br J Ophthalmol 2002;86:1330-5.

11. Pham TQ, Cugati S, Rochtchina E, et al. Age-related maculopathy and cataract surgery outcomes: visual acuity and health-related quality of life. Eye 2007;21:324-30.

12. Kessel L, Erngaard D, Flesner P, et al. Cataract surgery and age-related macular degeneration. An evidence-based update. Acta Ophthalmol 2015;93:593-600.

13. Mallah MK, Hart PM, McClure M, et al. Improvements in measures of vision and self-reported visual function after cataract extraction in patients with late-stage age-related maculopathy. Optom Vis Sci 2001;78:683-8.

14. Tuuminen R, Uusitalo-Jarvinen H, Aaltonen V, et al. The Finnish national guideline for diagnosis, treatment and follow-up of patients with wet age-related macular degeneration. Acta Ophthalmol 2017;95:1-9.

15. World Health Organization. World report on vision. 2019.

16. Mangione CM, Lee PP, Gutierrez PR, et al. Development of the 25-item National Eye Institute Visual Function Questionnaire. Arch Ophthalmol 2001;119:1050-8.

17. Schulze-Bonsel K, Feltgen N, Burau H, et al. Visual acuities "hand motion" and "counting fingers" can be quantified with the freiburg visual acuity test. Invest Ophthalmol Vis Sci 2006;47:1236-40.

18. Thylefors B, Chylack LT Jr, Konyama K, et al. A simplified cataract grading system. Ophthalmic Epidemiol 2002;9:83-95.

19. Danni R, Taipale C, Ilveskoski L, et al. Diabetes alone does not impair recovery from uneventful cataract surgery. Am J Ophthalmol 2019;198:37-44.

20. Teh BL, Megaw R, Borooah S, et al. Optimizing cataract surgery in patients with age-related macular degeneration. Surv Ophthalmol 2017;62:346-56.

21. Dag MY, Afrashi F, Nalcaci S, et al. The efficacy of "IOLVip Revolution" telescopic intraocular lens in age-related macular degeneration cases with senile cataract. Eur J Ophthalmol 2019;29:615-20.

Cite this article as: Taipale C, Grzybowski A, Tuuminen R. Effect of cataract surgery on quality of life for patients with severe vision impairment due to age-related macular degeneration. Ann Transl Med 2020;8(22):1543. doi: 10.21037/atm-2020-965 